\title{
A meta-analysis of observational studies on anticholinergic burden and fracture risk: evaluation of conventional burden scales
}

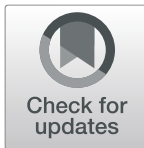

Yukari Ogawa $^{*^{*}}$ D, Toshinori Hirai ${ }^{2}$ and Kiyoshi Mihara ${ }^{1}$

\begin{abstract}
Background: Anticholinergic burden potentially increases the risk of fracture. Although there are various anticholinergic burden scales, little is known about the inter-scale compatibility regarding the relationship of anticholinergic burden with fracture risk. We performed meta-analysis to examine the association of fracture risk with anticholinergic burden measured using various scales.

Methods: Primary literature was retrieved from PubMed (1966 to March, 2021), the Cochrane Library (1974 to March, 2021), Scopus (1970 to March, 2021), and Ichushi-web (1983 to March, 2021). Cohort and case-control studies that evaluated the association between any fracture and anticholinergic drugs were included. Additionally, we included studies in which patients were administered anticholinergic drugs included on the anticholinergic risk scale (ARS), anticholinergic cognitive burden (ACB), anticholinergic drug scale, or drug burden index-anticholinergic component. Random effects models were used to calculate pooled relative risk (RR) and 95\% confidence interval $(\mathrm{Cl})$ due to heterogeneity among the studies. Publication bias was examined by funnel plots and the Begg's test.

Results: A total of 49 datasets from 10 studies were included in the meta-analysis. Six of the 10 studies included only patients aged over 65 years, who accounted for $93 \%$ of the total study population $(453,186 / 487,247)$. Metaanalysis indicated a positive relationship between use of anticholinergic drugs and fracture risk, regardless of the anticholinergic burden scale used. However, the relationship between anticholinergic burden and fracture risk varied depending on the scale used. Fracture risk increased linearly with increasing anticholinergic burden measured using ARS. ARS 1 point was associated with 28\% increase in fracture risk, ARS 1-2 point(s) with 39\%, ARS 2 points with 54\%, ARS 3 points with 66\%, and ARS $\geq 4$ points with 77\%. On the other hand, ACB 1 point and ACB 2 points were associated with similar fracture risk (pooled RR [95\% Cl]: overall; 1.28 [1.18-1.39], 1 point; 1.12 [1.061.18], 2 points; 1.15 [1.08-1.23]).
\end{abstract}

Conclusions: This result suggests that the relationship between anticholinergic drug burden and fracture risk may differ depending on the anticholinergic burden scale used.

Keywords: Anticholinergic drugs, Anticholinergic burden scale, Fracture, Meta-analysis

\footnotetext{
*Correspondence: y_ogawa@musashino-u.ac.jp

'Department of Pharmacy, Faculty of Pharmacy, Musashino University, 1-1-20

Shin-machi, Nishitokyo-shi, Tokyo 202-8585, Japan

Full list of author information is available at the end of the article
}

\section{$\triangle B M C$}

(c) The Author(s). 2021 Open Access This article is licensed under a Creative Commons Attribution 4.0 International License, which permits use, sharing, adaptation, distribution and reproduction in any medium or format, as long as you give appropriate credit to the original author(s) and the source, provide a link to the Creative Commons licence, and indicate if changes were made. The images or other third party material in this article are included in the article's Creative Commons licence, unless indicated otherwise in a credit line to the material. If material is not included in the article's Creative Commons licence and your intended use is not permitted by statutory regulation or exceeds the permitted use, you will need to obtain permission directly from the copyright holder. To view a copy of this licence, visit http://creativecommons.org/licenses/by/4.0/ The Creative Commons Public Domain Dedication waiver (http://creativecommons.org/publicdomain/zero/1.0/) applies to the data made available in this article, unless otherwise stated in a credit line to the data. 


\section{Background}

Anticholinergic drugs act on the muscarinic receptors in central and peripheral nervous systems and inhibit acetylcholine-mediated responses by binding to these receptors. A study of the trend of anticholinergic drug prescriptions from 1995 to 2010 reported an increase in prescriptions of these agents from 20.7\% in 1995 to $23.7 \%$ in 2010 [1] . Anticholinergic drugs comprise drugs with a broad spectrum of physiological effects, including psychotropic drugs, antiparkinsonian drugs, drugs for overactive bladder, and some antiarrhythmic drugs (such as disopyramide). Therefore, patients who receive prescriptions from more than one physician potentially have an increased anticholinergic burden due to concomitant use of anticholinergic drugs. The Beers criteria [2], the STOPP/START criteria [3], and the Japanese Guidelines for Medical Treatment and its Safety in the Elderly [4] recommend reassessment for appropriate use of anticholinergic drugs that can induce dry mouth, constipation, blurred vision, and cognitive dysfunction in older patients. According to some previous studies [5-7], olanzapine and paroxetine users have 1.49-fold and 1.21fold, respectively, higher risk of fracture compared with non-users. In contrast, other studies found no significant fracture risk of anticholinergic drugs $[8,9]$. Therefore, whether the use of anticholinergic drugs increases the fracture risk remains controversial.

A survey of 488,759 cases of hip fractures in Japan found that approximately $80 \%$ of fracture events were caused by accidental falls, and the number of fractures increased over time and tended to increase with age [10]. According to the Ministry of Health, Labour and Welfare comprehensive survey of living conditions in 2019, the number of people who needed nursing care due to a fracture or fall was the third highest among people requiring care, and accounted for $12.0 \%$ of the total number of people requiring care [11]. Fractures and falls reduce quality of life due to pain and loss of motor function [12]. As of 2020, 28.7\% of the total population in Japan were aged 65 and above, and 14.9\% were aged 75 and over [13]. It is important to implement risk management to avoid fractures and falls in Japan with a super-aged population.

Various scales have been developed to assess the anticholinergic burden, such as the anticholinergic risk scale (ARS) [14], the anticholinergic cognitive burden (ACB) $[15,16]$, the anticholinergic drug scale (ADS) [17], and the drug burden index-anticholinergic component (DBIAch) [18]. Many studies have reported the relationship between anticholinergic burden measured using various scales and fall-related fractures [19-21], though the direct causal mechanism of anticholinergic effect on fractures has not been proved to date. Reinold et al. [21] reported an association between anticholinergic burden and increased risk of fractures with possible doseexposure gradient in studies using ARS. However, it remains unclear whether the same trend between anticholinergic burden and fracture risk is observed when using other anticholinergic burden scales such as ACB, ADS and DBI-Ach. However, several reports have pointed out the discrepancy of risk scores assigned to drugs when using various anticholinergic burden scales [22-24]. For instance, these studies showed that the kappa values between ARS and ACB ranged from 0.25 to 0.43 (i.e., low consistency) [22-24]. It is important to address the discrepancies among anticholinergic burden scales which would affect the assessment of fracture risk. To our knowledge, no studies have systematically analyzed whether using different scales for calculating anticholinergic burden affects fracture risk assessment. In this study, we performed meta-analysis aiming to elucidate the association between fracture risk and anticholinergic burden measured using four widely used anticholinergic burden scale; namely, ARS, ACB, ADS and DBI-Ach.

\section{Methods}

\section{Data sources and searches}

We conducted meta-analysis in accordance with the Preferred Reporting Items for Systematic Reviews and Meta-analyses statement [25]. To assemble all of the relevant published studies and unpublished literature, the public databases used in the literature search were PubMed (1966 to March, 2021), the Cochrane Library (1974 to March, 2021), Scopus (1970 to March, 2021), and Ichushi-web (1983 to March, 2021). We combined the $\mathrm{MeSH}$ terms or keywords including "anticholinergic", "drug burden index", "cholinergic antagonists", "fracture" and "fractures, bone". In addition, we manually searched the reference lists in all the selected studies and related articles.

\section{Study selection}

The inclusion criteria of the present study were: (1) cohort studies or case-control studies that evaluated the association between anticholinergic drugs and fracture risk; (2) studies in which patients were administered anticholinergic drugs defined by ARS, ACB, ADS or DBI-Ach; (3) fracture was defined by objective measures such as the International Classification of Diseases; (4) the association between anticholinergic drugs and fracture was assessed using either the hazard ratio (HR), risk ratio (RR) or odds ratio (OR). We included studies in which $95 \%$ confidence intervals $(\mathrm{CI})$ were not listed, provided that the graphs were visually decipherable. Studies including patients younger than 15 years of age were excluded. Since we focused on the real-world data to evaluate the association of anticholinergic burden with 
fracture event, interventional studies, such as randomized controlled trials, were excluded. Duplicated studies, including different report using same population, were excluded. Two investigators ( $\mathrm{YO}$ and $\mathrm{TH}$ ) screened the articles independently using the inclusion and exclusion criteria. When there was a disagreement between the two investigators, a final decision was made after careful discussion.

\section{Data extraction}

Study design (cohort study, case-control study), number of patients, sex of patients, age of patients, names of anticholinergic drugs or scores on anticholinergic burden scales, country in which the study was performed, anatomical site of fracture, follow-up period, and confounders were extracted from each study. In addition, for studies that did not document the anticholinergic burden scores in the manuscript but identified the names of anticholinergic agents, we manually calculated anticholinergic burden scores using ARS, ACB and ADS. The confounder-adjusted RR was used as a measure of the association between use of anticholinergic drugs and fracture risk. In case a study had reported stratified population data, we used all the datasets for the metaanalysis unless patient overlap existed.

\section{Assessment of risk of bias in included studies}

The quality of each study was assessed using the risk of bias assessment tool for non-randomized studies (RoBANS) [26]. The tool consists of six categories: selection of patients, confounding variables, measurement of exposure, blinding of outcome assessments, incomplete outcome data, and selective outcome reporting. According to RoBANS, we assessed the risk of bias as low, high, or unclear based on adjustment of age and comorbidities, objective measurement of fracture event, and missing data. Then overall risk of bias was assigned to each study as follows; included studies that were categorized as having an overall low risk of bias ( $\leq 1$ category evaluated as having high or unclear risk of bias), medium risk of bias (two categories evaluated as having high or unclear risk of bias) or high risk of bias ( $\geq 3$ categories evaluated as having high or unclear risk of bias) [27].

\section{Comparison between ARS and ACB for fracture risk in the same cohort}

ARS and ACB were frequently used for calculation of anticholinergic burden in the included studies, whereas ADS and DBI-Ach were less commonly used. Thus, we compared whether there was a difference in the estimated fracture risk related to anticholinergic burden calculated using ARS and ACB in the same cohort. Among the included studies, if both ARS and ACB scores could be calculated within the same cohort of individuals, we used them for performing meta-analysis to evaluate the relationship of fracture risk with anticholinergic burden calculated using ARS and ACB separately. Based on the $R R$ for fracture risk calculated in our meta-analysis, we classified them into five categories: low fracture risk (RR 1.0 to 1.2 ), medium/low risk (RR 1.2 to 1.4 ), medium risk (RR 1.4 to 1.6), medium/high risk (RR 1.6 to 1.8 ), and high risk (RR 1.8 and higher). Then, we examined the concordance between ARS and ACB with respect to the relationship between anticholinergic burden score and risk category.

\section{Data synthesis and analysis}

The association between anticholinergic drugs and fracture events was assessed by RR and 95\% CI. Because the absolute value of fracture risk is small, OR was judged to be comparable to $R R[28,29]$. Therefore, for casecontrol studies, OR was replaced by RR as an alternative value for data analysis. We judged HR was comparative to RR under proportional hazard assumption [30]. When there were two or more included studies for an endpoint, we performed a meta-analysis on the studies and calculated the integrated RR and 95\% CI using random effects methods (Mantel-Haenszel). Inter-study heterogeneity was assessed by $\mathrm{I}^{2}$ statistic $\left(\mathrm{I}^{2} \geq 75 \%\right.$ indicates substantial heterogeneity) [31]. Publication bias was examined by funnel plots and the Begg's test [32]. Funnel plots were constructed by plotting RR as effect size estimate on the horizontal axis and the standard error of $\log R R$ as sample size on the vertical axis, and whether the distribution was symmetrical was determined visually. Furthermore, publication bias was judged to be present when the Begg's test yielded $P<0.05$. A subgroup analysis was conducted in elder (65 years and over) patients. Data were analyzed using Stata15 (College Station, TX, USA). A $P$ value less than 0.05 was considered significant.

\section{Results}

Study retrieval and characteristics of included studies

The primary literature search retrieved 327 studies comprising 103 from PubMed, 54 from Cochrane Library, 138 from Scopus, 31 from Ichushi-web, and 1 from manual search (Fig. 1). Two investigators ( $\mathrm{YO}$ and $\mathrm{TH}$ ) independently reviewed the articles using the inclusion and exclusion criteria and finally included 10 studies [19, 20, 33-40]. A summary of the studies analyzed is shown in Table 1 and Table 2. The total sample size was 487, 247 patients. Patients in five $[20,33,35,37,39]$ of the ten studies were aged 65 years and older. Three [20, 36, 37] of the ten studies were conducted in Asia, but none of them were conducted in Japan. Regarding study design, eight studies were cohort studies [20,33-37, 39, $40]$ and two were case-control studies [19, 38]. Seven 


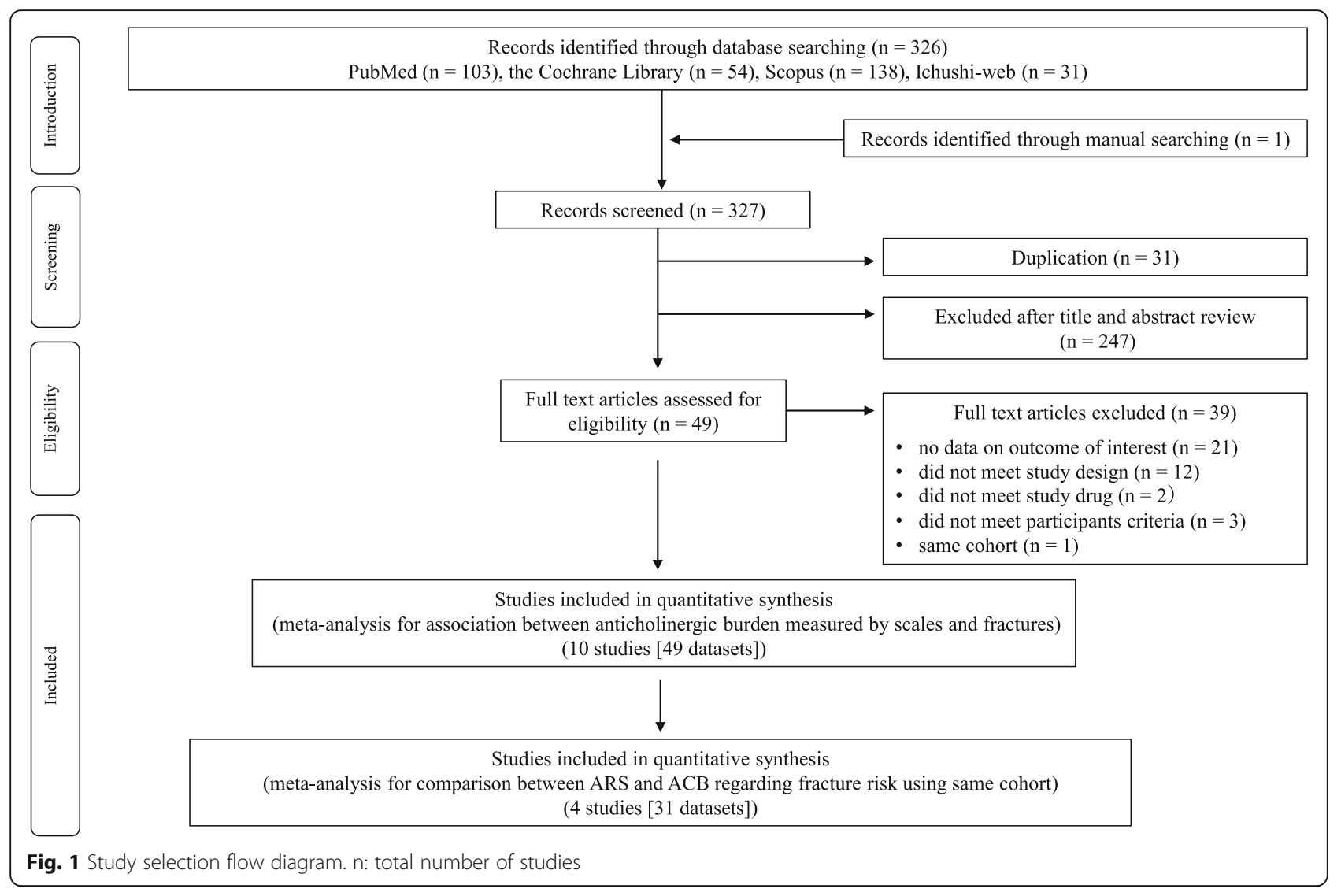

$[20,33,34,37-40]$ of the ten studies utilized ARS to calculate anticholinergic exposure. Six $[20,33,35,36,39$, 40] of the ten studies utilized ACB to calculate anticholinergic burden. In all the included studies, the confounders used in the analyses of fracture risk ratios were mainly age, sex, comorbidities, and concomitant medications. We retrieved a total of 49 datasets from the included studies for performing meta-analysis. Five studies $[19,20,34,37,38]$ had shown OR as the fracture risk indicator, and the incidence of fractures among the anticholinergic group in these studies was around 10\% except for the study of Lu et al. (25.7\%) [37]. Results of assessment for risk of bias of individual studies are shown in Table 3. Analysis using RoBANS indicated an overall low risk of bias in all the studies except the study of Ishida et al. [35].

\section{Association between anticholinergic burden and fracture risk \\ ARS}

A total of 25 datasets from 7 studies [20, 33, 34, 37-40] were included in the meta-analysis for ARS. Forest plot of all RRs of fracture risk associated with anticholinergic drugs in individual studies and overall RR are shown in Fig. 2. The fracture risk was significantly higher in the anticholinergic group compared to the non- anticholinergic group (pooled RR [95\% CI]: 1.49 [1.401.59]). Furthermore, the risk of fractures increased linearly as anticholinergic burden increased. ARS 1 point was associated with $28 \%$ increase in fracture risk, ARS 1-2 point(s) with $39 \%$, ARS 2 points with $54 \%$, ARS 3 points with $66 \%$, and $A R S \geq 4$ points with $77 \%$.

\section{$A C B$}

A total of 21 datasets from 6 studies [20, 33, 35, 36, 39, 40] were included in the meta-analysis for ACB. Forest plot of all RRs of fracture risk associated with anticholinergic drugs in individual studies and overall $R R$ are shown in Fig. 3. The fracture risk was significantly higher in the anticholinergic group compared to the non-anticholinergic group (pooled RR [95\% CI]: 1.28 [1.18-1.39]). ACB 1 point and ACB 2 points were associated with similar fracture risk (pooled RR $[95 \% \mathrm{CI}]$ : 1.12 [1.06-1.18] and 1.15 [1.08-1.23], respectively). On the other hand, ACB 3 points was associated with $32 \%$ increase in fracture risk, and $\mathrm{ACB} \geq 4$ points with $58 \%$.

\section{ADS}

A total of 6 datasets from 4 studies [19, 33, 39, 40] were included in the meta-analysis of ADS. Forest plot of all RRs of fracture risk associated with anticholinergic drugs in individual studies and overall RR are shown in 
Table 1 Characteristics of cohort studies included in the present meta-analysis

\begin{tabular}{|c|c|c|c|c|c|c|c|c|}
\hline Study & Country & $\begin{array}{l}\text { Sample } \\
\text { size } \\
\text { (AC } \\
\text { drug } \\
\text { user, } \\
\text { (n)) }\end{array}$ & $\begin{array}{l}\text { Female } \\
(\%)\end{array}$ & Age & $\begin{array}{l}\text { Anatomical site } \\
\text { of fracture }\end{array}$ & $\begin{array}{l}\text { AC } \\
\text { burden } \\
\text { scale }\end{array}$ & $\begin{array}{l}\text { Mean } \\
\text { follow-up }\end{array}$ & Adjusted for confounders \\
\hline $\begin{array}{l}\text { Bali et al. } \\
\text { (2016) } \\
{[33]}\end{array}$ & USA & $\begin{array}{l}9240 \\
(4620)\end{array}$ & 67 & $\geq 65 \mathrm{yr}$ & hip & $\begin{array}{l}\text { ARS, } \\
\text { ACB, } \\
\text { ADS* }\end{array}$ & 2.0 years & $\begin{array}{l}\text { age, sex, race, co-medications, } \\
\text { and illness history during 1-year baseline period }\end{array}$ \\
\hline $\begin{array}{l}\text { Crispo } \\
\text { et al. } \\
(2016) \\
{[34]}\end{array}$ & Canada & $\begin{array}{l}16,302 \\
(13,839)\end{array}$ & 47 & $\begin{array}{l}\geq 70 y r: \\
82.3 \%\end{array}$ & any fracture & ARS & $\begin{array}{l}3-6 \text { days: } \\
2463 \\
\text { persons } \\
7-30 \text { days: } \\
5799 \\
\text { persons } \\
\geq 31 \text { days: } \\
141 \text { persons }\end{array}$ & $\begin{array}{l}\text { age, sex, race, length of stay, Elixhauser } \\
\text { comorbidity score, census region, urban/rural } \\
\text { status, hospital size (number of beds), and hospital } \\
\text { teaching status }\end{array}$ \\
\hline $\begin{array}{l}\text { Hsu et al. } \\
(2017) \\
{[20]}\end{array}$ & Taiwan & $\begin{array}{l}116,043 \\
(43,301)\end{array}$ & 50 & $\geq 65 \mathrm{yr}$ & any fracture & $\begin{array}{l}\text { ARS, } \\
\text { ACB, } \\
\text { DBI-Ach }\end{array}$ & 8.3 years & $\begin{array}{l}\text { sex and time-varying comorbidities (annually mea- } \\
\text { sured by Carlson Comorbidity Index) }\end{array}$ \\
\hline $\begin{array}{l}\text { Ishida } \\
\text { et al. } \\
(2019) \\
{[35]}\end{array}$ & USA & $\begin{array}{l}60,007 \\
(3745)\end{array}$ & 56 & $\geq 65 \mathrm{yr}$ & $\begin{array}{l}\text { hip, femur, pelvis, } \\
\text { foot, arm, hand, } \\
\text { or axial skeleton }\end{array}$ & $A C B^{* *}$ & $\begin{array}{l}243 \\
\text { days }\end{array}$ & $\begin{array}{l}\text { age, sex, race, duration on dialysis, network, BMI, } \\
\text { alcohol dependence, } \\
\text { coronary artery disease, cancer, other cardiac } \\
\text { disease, dysrhythmia, } \\
\text { congestive heart failure, cerebrovascular disease, } \\
\text { diabetes, } \\
\text { drug dependence, opioid dependence, } \\
\text { hypertension, } \\
\text { inability to ambulate, inability to transfer, } \\
\text { chronic obstructive pulmonary disease, peripheral } \\
\text { vascular disease, tobacco dependence, dementia, } \\
\text { depression, seizure/epilepsy } \\
\text { liver disease, medication burden, and concomitant } \\
\text { medications }\end{array}$ \\
\hline $\begin{array}{l}\text { Kao et al. } \\
(2018) \\
{[36]}\end{array}$ & Taiwan & $\begin{array}{l}14,635 \\
(2927)\end{array}$ & 69 & $\begin{array}{l}52.0 \pm \\
16.9 \mathrm{yr} \\
\text { (study } \\
\text { cohort) } \\
51.9 \pm \\
17.1 \mathrm{yr} \\
\text { (control) }\end{array}$ & any fracture & $A C B^{* * *}$ & 3.0 years & $\begin{array}{l}\text { monthly income, geographical region, urbanization } \\
\text { level, and comorbidities }\end{array}$ \\
\hline $\begin{array}{l}\text { Lu et al. } \\
\text { (2015) } \\
{[37]}\end{array}$ & Taiwan & $\begin{array}{l}59,042 \\
(7461)\end{array}$ & 49 & $\geq 65 \mathrm{yr}$ & any fracture & ARS & $\begin{array}{l}7.95 \pm 3.03 \\
\text { years }\end{array}$ & age, sex, and time-varying comorbidities \\
\hline $\begin{array}{l}\text { Moga } \\
\text { et al. } \\
\text { (2013) } \\
{[39]}\end{array}$ & USA & $\begin{array}{l}6594 \\
(1125)\end{array}$ & 4 & $\geq 65 \mathrm{yr}$ & $\begin{array}{l}\text { hip or } \\
\text { any fracture }\end{array}$ & $\begin{array}{l}\text { ARS, } \\
\text { ACB, } \\
\text { ADS }^{* * * *}\end{array}$ & $\begin{array}{l}\text { AC drug } \\
\text { users: } 49 \\
\text { days } \\
\text { (median) } \\
\text { AC drug } \\
\text { nonusers: } \\
95 \text { days } \\
\text { (median) }\end{array}$ & $\begin{array}{l}\text { demographic characteristics, continence status } \\
\text { (bladder and bowel), continence management, } \\
\text { preexistent urinary tract infections, body mass } \\
\text { index, comorbidities, other medication use, } \\
\text { cognitive status, mobility at baseline }\end{array}$ \\
\hline $\begin{array}{l}\text { Sørensen } \\
\text { et al. } \\
\text { (2013) } \\
{[40]}\end{array}$ & Denmark & $\begin{array}{l}2224 \\
(1216)\end{array}$ & $\begin{array}{l}\text { not } \\
\text { mention }\end{array}$ & $\begin{array}{l}68.6 \pm \\
12.8 \mathrm{yr}\end{array}$ & hip & $\begin{array}{l}\text { ARS, } \\
\text { ACB, } \\
\text { ADS }^{* * * * *}\end{array}$ & $\begin{array}{l}\text { not } \\
\text { mention }\end{array}$ & $\begin{array}{l}\text { age at diagnosis (schizophrenia), sex, alcohol } \\
\text { misuse, somatic score }\end{array}$ \\
\hline
\end{tabular}

AC: anticholinergic, ARS: anticholinergic risk scale, ACB: anticholinergic cognitive burden, ADS: anticholinergic drug scale

*AC drug used was paroxetine, which is 1 point on ARS, 3 points on $A C B$, and 1 point on ADS

* AC drugs used were amitriptyline, paroxetine, doxepin, nortriptyline, imipramine, desipramine and clomipramine, which are 3 points on $A C B$; and protriptyline which is not listed on ACB. Since less than $10(0.01 \%)$ patients were taking protriptyline, we categorized all drugs use as ACB 3 points

*** AC drugs used were oxybutynin, trospium, tolterodine, solifenacin and propiverine, which are 3 points on $A C B$

**** AC drug used was oxybutynin, which is 3 points on ARS, ACB, and ADS

***** AC drugs used included risperidone, which is 1 point on ARS and ACB; quetiapine which is 1 point on ARS and 3 points on ACB; olanzapine, which is 2 points on ARS, 3 points on ACB and 1 point on ADS; and aripiprazole, which is 1 point on ACB

******Follow-up period was calculated using fracture rate (6 events per 100 person-years) and number of fractures (4\% of the cohort) described in the article 
Table 2 Characteristics of case-control studies included in the present meta-analysis

\begin{tabular}{|c|c|c|c|c|c|c|c|c|}
\hline Study & Country & $\begin{array}{l}\text { Sample } \\
\text { size } \\
\text { (case/ } \\
\text { control) }\end{array}$ & Age & $\begin{array}{l}\text { Female } \\
(\%)\end{array}$ & $\begin{array}{l}\text { Anatomical } \\
\text { site of } \\
\text { fracture }\end{array}$ & $\begin{array}{l}\text { AC } \\
\text { burden } \\
\text { scale }\end{array}$ & AC exposure & Adjusted for confounders \\
\hline $\begin{array}{l}\text { Chatterjee } \\
\text { et al. (2016) } \\
\text { [19] }\end{array}$ & USA & $\begin{array}{l}202,260 \\
(40,452 / \\
161,808)\end{array}$ & $\begin{array}{l}81.1 \pm \\
7.4 \mathrm{yr}\end{array}$ & 85 & hip or femur & ADS & $\begin{array}{l}\text { prescribed } \\
30-90 \text { days } \\
\text { before } \\
\text { fracture }\end{array}$ & $\begin{array}{l}\text { age, sex, medications, race, medications } \\
\text { (cardiovascular drugs, antidepressants, } \\
\text { anticonvulsants, antipsychotics, and } \\
\text { benzodiazepines), and comorbidities (dementia, } \\
\text { mood disorders, anxiety, schizophrenia, Parkinson's } \\
\text { disease, insomnia, cerebrovascular events, } \\
\text { osteoarthritis, osteoporosis, rheumatoid arthritis), and } \\
\text { duration of depression }\end{array}$ \\
\hline $\begin{array}{l}\text { Machado- } \\
\text { Duque et al. } \\
\text { (2018) [38] }\end{array}$ & Colombia & $\begin{array}{l}900 \\
(300 / \\
600)\end{array}$ & $\begin{array}{l}81.6 \pm \\
8.9 y r\end{array}$ & 71 & hip & ARS & $\begin{array}{l}\text { prescribed } 30 \\
\text { days before } \\
\text { fracture }\end{array}$ & $\begin{array}{l}\text { use of statins, proton pump inhibitors, } \\
\text { corticosteroids, oral antidiabetics, polypharmacy ( } \geq 5 \\
\text { drugs), and treatment city }\end{array}$ \\
\hline
\end{tabular}

$A C$ anticholinergic, $A R S$ anticholinergic risk scale, $A D S$ anticholinergic drug scale

Additional file 1 . The fracture risk was significantly higher in the anticholinergic group compared to the non-anticholinergic group (pooled RR [95\% CI]: 1.19 [1.08-1.31]). The fracture risk was comparable for ADS 1 point and ADS 2 points, although only one dataset [40] for available for ADS 2 points.

\section{DBI-Ach}

The study of Hsu et al. [20] assessed the fracture risk and anticholinergic burden using DBI-Ach, and DBIAch scores were divided into two categories $(0<\mathrm{DBI}-$ Ach $\leq 0.5$ and $0.5<$ DBI-Ach $\leq 1)$. We performed metaanalysis using 6 datasets. The fracture risk was significantly higher in the anticholinergic group compared to the non-anticholinergic group (pooled RR [95\% CI]: 1.46
[1.36-1.57]). Fracture risk showed a linear increase with increase in anticholinergic burden (pooled RR [95\% CI] for $0<\mathrm{DBI}-\mathrm{Ach} \leq 0.5$ : 1.39 [1.28-1.51], for $0.5<\mathrm{DBI}-$ Ach $\leq 1: 1.60$ [1.47-1.73]). This study included only patients aged 65 years and older.

\section{Subgroup analysis}

We next focused on elder patients aged 65 years and older. In the subgroup analysis, we included six studies that investigated only patients aged 65 years and older $[20,33,35,37,39]$ together with the study of Chatterjee et al. [19] that included patients with mean age of $81.1 \pm$ 7.4 years, and we estimated that $95 \%$ of the eligible patients were older than 65 years. Additional file 2 summarizes the pooled RRs associated with anticholinergic

Table 3 Quality assessment using risk of bias assessment tool for non-randomized studies

\begin{tabular}{|c|c|c|c|c|c|c|c|}
\hline Study & $\begin{array}{l}\text { Selection of } \\
\text { participants }\end{array}$ & $\begin{array}{l}\text { Confounding } \\
\text { variables }\end{array}$ & $\begin{array}{l}\text { Measurement } \\
\text { of exposure }\end{array}$ & $\begin{array}{l}\text { Blinding of } \\
\text { outcome } \\
\text { assessments }\end{array}$ & $\begin{array}{l}\text { Incomplete } \\
\text { outcome data }\end{array}$ & $\begin{array}{l}\text { Selective } \\
\text { outcome } \\
\text { reporting }\end{array}$ & $\begin{array}{l}\text { Overall risk } \\
\text { of bias }\end{array}$ \\
\hline Bali et al. (2016) [33] & unclear & low & low & low & low & low & low \\
\hline $\begin{array}{l}\text { Chatterjee et al. } \\
\text { (2016) [19] }\end{array}$ & low & low & low & low & low & unclear & low \\
\hline $\begin{array}{l}\text { Crispo et al. (2016) } \\
\text { [34] }\end{array}$ & unclear & low & low & low & low & low & low \\
\hline $\begin{array}{l}\text { Hsu et al. (2017) } \\
\text { [20] }\end{array}$ & unclear & low & low & low & low & low & low \\
\hline $\begin{array}{l}\text { Ishida et al. (2019) } \\
\text { [35] }\end{array}$ & unclear & low & low & low & unclear & low & medium \\
\hline $\begin{array}{l}\text { Kao et al. (2018) } \\
{[36]}\end{array}$ & low & low & low & low & unclear & low & low \\
\hline Lu et al. (2015) [37] & unclear & low & low & low & low & low & low \\
\hline $\begin{array}{l}\text { Machado-Duque } \\
\text { et al. (2018) [38] }\end{array}$ & low & low & low & low & low & high & low \\
\hline $\begin{array}{l}\text { Moga et al. (2013) } \\
\text { [39] }\end{array}$ & low & low & low & low & low & low & low \\
\hline $\begin{array}{l}\text { Sørensen et al. } \\
\text { (2013) [40] }\end{array}$ & low & low & low & low & low & low & low \\
\hline
\end{tabular}




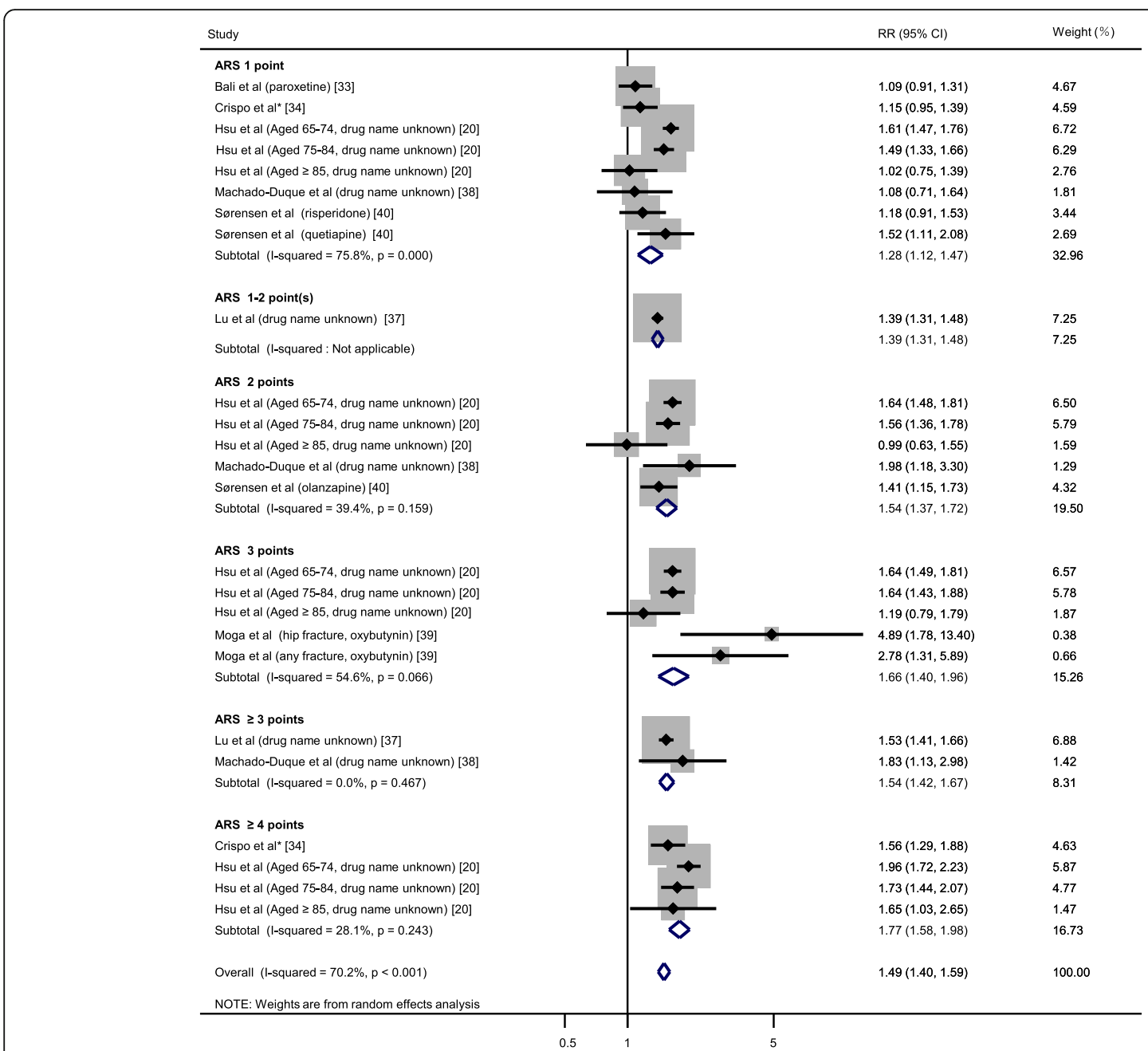

Fig. 2 Forest plot of meta-analysis of fracture risk associated with anticholinergic burden using ARS. Gray box ( $\mathbf{\square})$ represents sample size in each study. Risk ratio (RR) and 95\% confidence interval (Cl) are shown. The analysis was performed using Mantel-Haenszel method with random effects model. *Drugs with ARS 1 point used were carbidopa-levodopa (60.7\%), quetiapine (9.6\%), metoclopramide (8.7\%), pramipexole (8.4\%), haloperidol (6.4\%), entacapone (6.3\%), risperidone (5.1\%), mirtazapine (4.9\%), paroxetine (4.4\%), trazodone (4.1\%), ranitidine (3.5\%), selegiline (2.5\%), ziprasidone (0.9\%), and methocarbamol (0.6\%). Drugs with ARS 2 points used were olanzapine (4.6\%), amantadine (4.1\%), tolterodine (3.3\%), loratadine (2.1\%), prochlorperazine (2.1\%), loperamide (1.8\%), cyclobenzaprine (1.3\%), nortriptyline (0.6\%), cetirizine (0.5\%), clozapine $(0.4 \%)$, cimetidine (0.3\%), desipramine (0.1\%), and pseudoephedrine $(<0.01 \%)$. Drugs with ARS 3 points used were diphenhydramine $(7.6 \%)$, promethazine (6.1\%), oxybutynin (3.4\%), atropine (2.6\%), hydroxyzine (2.4\%), benztropine (2.2\%), amitriptyline (1.7\%), meclizine $(1.5 \%)$, hyoscyamine $(0.6 \%)$, dicyclomine $(0.6 \%)$, tizanidine $(0.3 \%)$, chlorpromazine $(0.3 \%)$, perphenazine $(0.3 \%)$, cyproheptadine $(0.3 \%)$, imipramine $(0.2 \%)$, carisoprodol $(0.2 \%)$, thioridazine $(0.1 \%)$, chlorpheniramine $(0.1 \%)$, fluphenazine $(0.1 \%)$, trifluoperazine $(0.1 \%)$, and thiothixene $(0.1 \%)$

drugs in elder patients. For ARS, ACB and ADS, fracture risk was higher in users of anticholinergic drugs compared to non-users of anticholinergic drugs (pooled RR [95\% CI]: $1.53[1.42-1.65], 1.29[1.17-1.41]$ and 1.15 [1.04-1.27], respectively). The results for DBI-Ach in elder patients are described above.

\section{Publication bias}

Funnel plots of the study data for the four anticholinergic burden scales used in meta-analysis are shown in Additional file 3. Regarding ADS, the funnel plot was asymmetric and the result of the Begg's test showed statistically significant publication bias $(P=0.039)$.

\section{Comparison between ARS and ACB for fracture risk in same cohort}

Four studies [20,33, 39, 40] utilized both ARS and ACB to measure anticholinergic burden within the same cohort. We used the cohort data in which both anticholinergic burden scales were used simultaneously to validate the result of our meta-analysis. Figure 4 presents a summary of the individual meta-analyses performed. A linear relationship was found between fracture risk and 


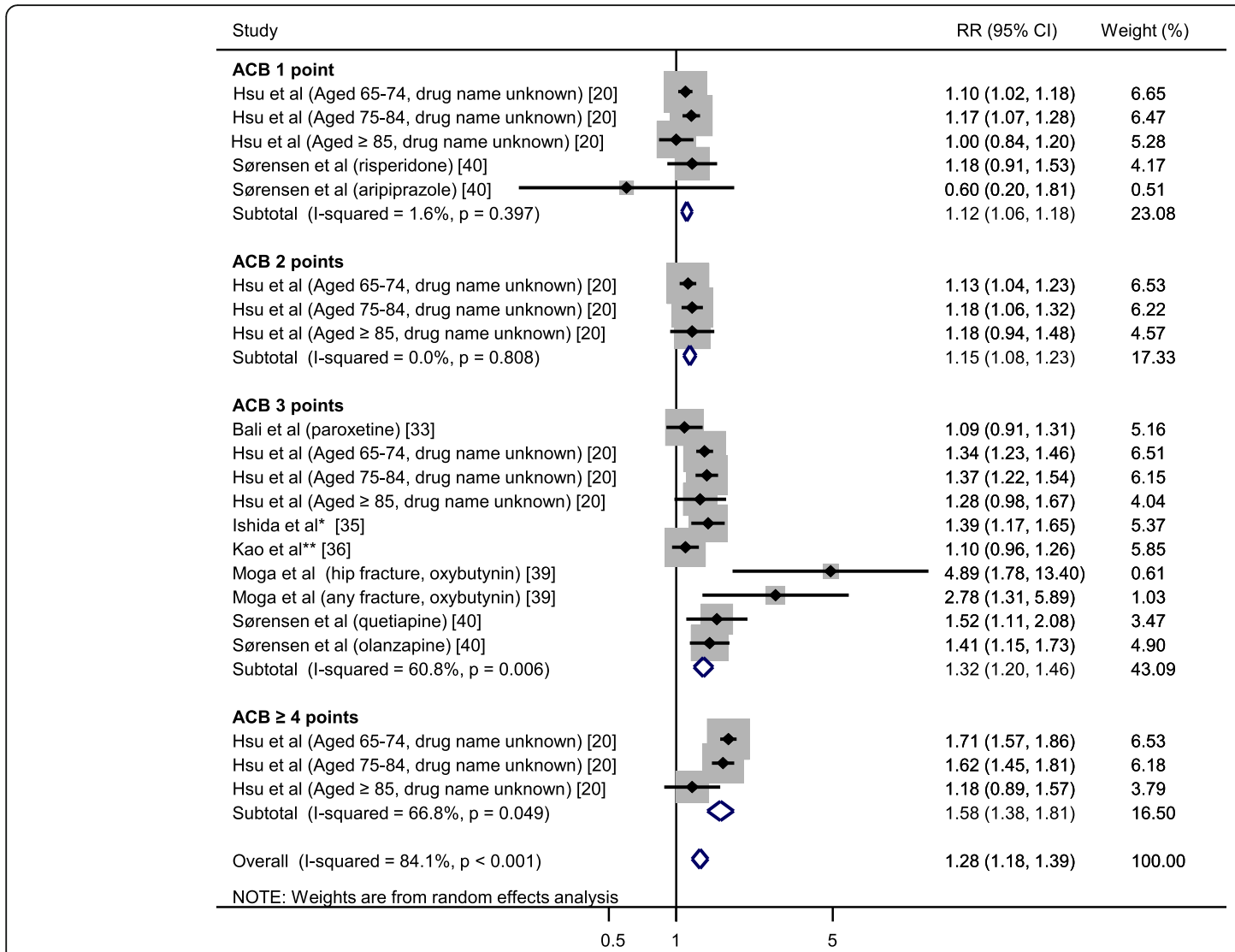

Fig. 3 Forest plot of meta-analysis of fracture risk associated with anticholinergic burden using ACB. Gray box (⿶) represents sample size in each study. Risk ratio (RR) and 95\% confidence interval (Cl) are shown. The analysis was performed using Mantel-Haenszel methods with random effects model. *Anticholinergic drugs used were amitriptyline (3\%), paroxetine (2\%), doxepin (0.6\%), nortriptyline $(0.5 \%)$, imipramine $(0.1 \%)$, desipramine $(0.04 \%)$, clomipramine $(0.01 \%)$, and protriptyline $(0.01 \%)$. All drugs except protriptyline are listed as ACB 3 points. However, since few patients used protriptyline, we categorized all anticholinergic drugs used as ACB 3 points. **Anticholinergic drugs used were oxybutynin, trospium, tolterodine, solifenacin, and propiverine. All drugs are listed as ACB 3 points

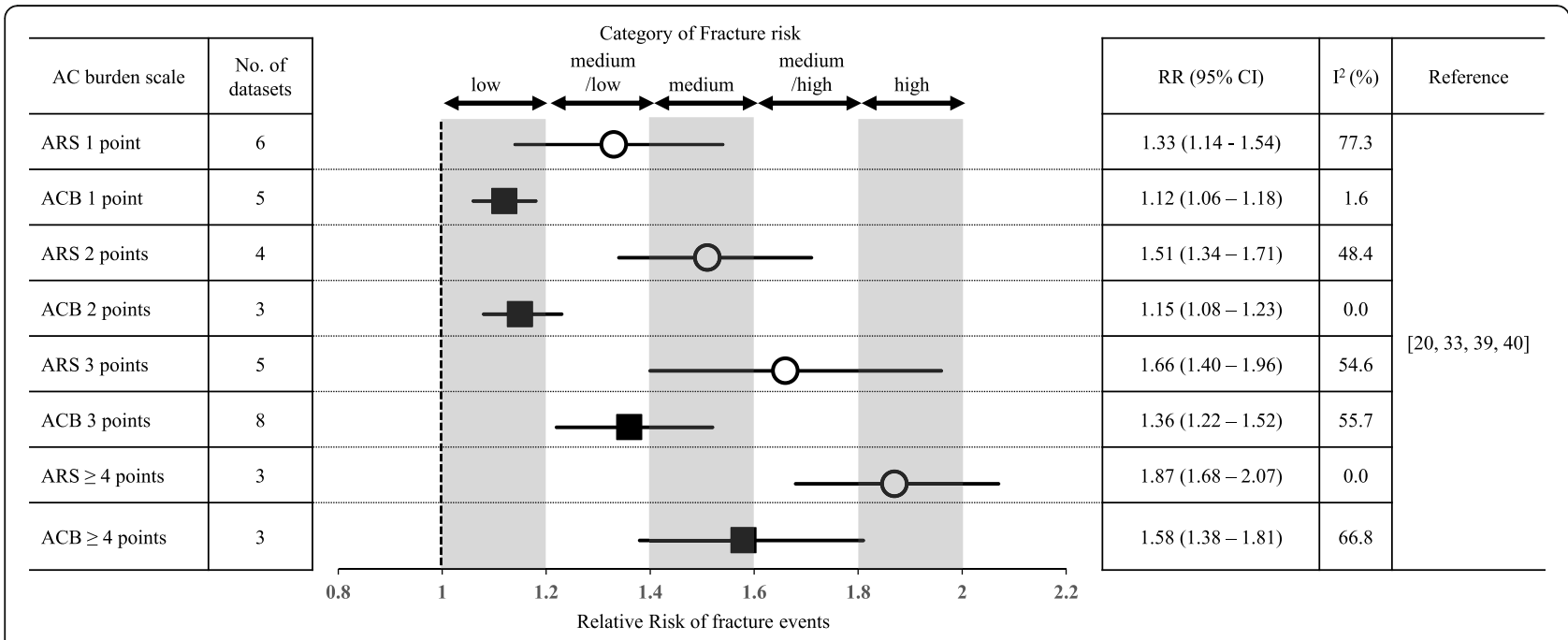

Fig. 4 Summary of results of meta-analyses including four studies that measured anticholinergic burden using both ARS and ACB 
anticholinergic burden measured by ARS, but not ACB. In addition, RRs of ARS 1 point and ACB 3 points were comparable (pooled RR [95\% CI]: 1.33 [1.14-1.54] and 1.36 [1.22-1.52], respectively). The drugs used in ARS 1point group were paroxetine, risperidone and quetiapine; while the drugs used in ACB 3-point group were paroxetine, oxybutynin, quetiapine and olanzapine (the study of Hsu et al. [20] did not mention the drugs in detail). Forty-nine drugs are included in ARS [14] and 99 drugs in ACB $[15,16], 35$ of which are included in both ARS and ACB. Additional file 4 shows a summary of the 35 overlapping drugs. Of the 35 drugs, 22 (62.9\%) showed concordance between ARS and ACB scores, but all the 22 drugs showed different fracture risk categories when using ARS and ACB. Metcavamol, paroxetine, and quetiapine were in the same fracture risk category, but these drugs scored differently in ARS and ACB (ARS: 1 point, ACB: 3 points). Of the 22 drugs with concordant ARSACB scores, 18 had a 2-rank difference in fracture risk when using the two scales (for example, amantadine: "medium" fracture risk using ARS, "low" fracture risk using $\mathrm{ACB}$ ). In addition, the 14 drugs listed on ARS, not on ACB, included 4 (28.6\%) with 3 points [carisoprodol (not approved in Japan), fluphenazine, thiothixene (not approved in Japan) and tizanidine], while the 64 drugs listed on $\mathrm{ACB}$, not on ARS, included 45 (70.3\%) with 1 or 2 points (ACB 1 point: 36 drugs, ACB 2 points: 9 drugs) and were categorized as "low" fracture risk.

\section{Discussion}

This study found that regardless of which anticholinergic burden scale was used to assess anticholinergic burden, anticholinergic drug users had significantly increased fracture risk by 19 to $49 \%$ compared to non-users. Interestingly, however, the relationship between anticholinergic burden and fracture risk showed different trends depending on the anticholinergic burden scale used. Reinold et al. [21] have reported an association of anticholinergic burden with increased risk of fractures with possible dose-exposure gradient in studies using ARS. Our meta-analyses suggested that the risk of fractures increased dose-dependently in studies using ARS as well as in a single study using DBI-Ach. Our analysis on DBI-Ach included 3 datasets with different age groups from the same study. Therefore, its extrapolation to broader population could be limited. ACB exhibits a trend different from other anticholinergic burden scales. When using $\mathrm{ACB}$, although high anticholinergic burden (3 or 4 points) was associated with higher fracture risk than low anticholinergic burden (1 or 2 points), fracture rate did not differ between ACB 1 point and 2 points (RR: 1.1 and 1.15, respectively).

ARS, ACB, DBI-Ach, and ADS are widely used to assess the anticholinergic burden. In ARS, drugs are rated from 0 (no or low risk of anticholinergic adverse effects) to 3 (high potential risk). In ACB, drugs with possible anticholinergic effects are rated from 1 (no known clinically relevant negative cognitive effects) to 3 (clinically relevant negative cognitive effects). ADS ranks the anticholinergic effects of drugs in a 4-point scale of 0 (no known anticholinergic activity) to 3 (significantly marked anticholinergic activity). For each of these anticholinergic burden scales (ARS, ACB and ADS), the total anticholinergic drug exposure for an individual is the sum of the scores for all drugs. The DBI is a pharmacological risk assessment tool that calculates exposure to both anticholinergic (DBI-Ach) and sedative drugs. DBI is based on the principle of cumulative exposure and dose response.

In the included studies, ARS and ACB were commonly used to calculate anticholinergic burden. Therefore, using the same cohort, we examined whether fracture risk differs when ARS and ACB are used to measure anticholinergic burden. We divided fracture risk into five categories based on the results of our meta-analyses, ranging from "low" to "high" (Fig. 4). A previous study has reported that less than $50 \%$ of patients were classified into the same burden category by different scales including ARS and ACB, and that the level of anticholinergic burden varies depending on the assessment scale used [24]. In our analysis, ACB 1 point and ACB 2 points were both associated with "low" fracture risk. On the other hand, ARS 1 point and ACB 3 points were both associated with "medium/low" fracture risk. The discrepancy between ARS and ACB may influence the risk assessment for preventing fracture events. Of 35 drugs included in both ARS and ACB, 22 drugs have concordant ARS-ACB scores, while none of these drugs are concordant in category of fracture risk (Additional file 4). On the other hand, three drugs (methocabamol, paroxetine and quetiapine) that are in the same category of fracture risk have different scores in ARS and ACB. ARS was developed to predict the risk of anticholinergic adverse effects such as falls, dry mouth, dry eyes, dizziness, and confusion [14]. On the other hand, ACB was developed to predict the risk of cognitive impairment $[15,16]$. The different methodology by which these scales were developed may give rise to the discrepancy in fracture risk prediction.

In general, pharmacokinetic changes such as decreased hepatic and renal clearance and pharmacodynamic changes such as increased sensitivity to anticholinergic drugs occur in elder people. Therefore, this population is expected to be at increased risk of drug interactions and adverse effects. In the subgroup of patients aged 65 years or older, our study showed that those who used anticholinergic drugs had increased fracture risk compared to non-users of anticholinergic drugs, regardless 
of the anticholinergic burden scale used. In this study, the result of meta-analysis for the elder population did not show remarkably higher fracture risk when compared to the overall result of the total study population. This finding may reflect that the overall result of our meta-analysis was derived mainly from elder patients, because $6[19,20,33,35,37,39]$ of 10 studies included only patients aged over 65 years, who accounted for $93 \%$ of the total study population $(453,186 / 487,247)$. The study of Kao et al. [36] included younger patients (mean age 52 ages) than the subjects in the other studies. However, the reported RR in the study of Kao et al. [36] was comparable with those in other studies (Fig. 3).

The meta-analyses in this study showed that heterogeneity tended to be high (e.g., $\mathrm{I}^{2} 70.2 \%$ in Fig. $2, \mathrm{I}^{2}$ $84.1 \%$ in Fig. 3). As visual inspection from the forest plot, the study reported by Moga et al. [39] seemed to show higher fracture risk compared with the other studies. The major differences are the shorter observation period (49 days for anticholinergic users and 95 days for non-users) and the smaller proportion of women (4\%) in the study of Moga et al. [39] compared to the others. However, we could not find any accountable relationships between higher fracture risk and either shorter observation or smaller proportion of women.

Five $[19,33,38-40]$ of the ten included studies focused on the risk of hip or femur fractures, the biggest concern during fall accidents, in anticholinergic drug users compared to non-users. Psychotropics, a typical class of anticholinergic drugs, are well known to cause falls [41]. Our result indicates that anticholinergic drugs may increase not only the risk of falls, but also the risk of fractures. A study of Japanese older population has reported that anticholinergic burden according to ARS was associated positively with the risk of hip or femur fractures [42]. Our finding suggests the same trend, although no Japanese studies were included in our metaanalysis.

Our study had several limitations. First, we were unable to evaluate whether the nursing and care settings were comparable in all the studies included in the metaanalysis. In the case of fall-related fractures, it is important to ensure that the living environment does not induce falls and to establish a preventive system for early detection of falls. We cannot completely exclude the possibility that environmental setting has a confounding effect on the association between anticholinergic drugs and fracture risk. Second, we did not evaluate the association between decreased bone density or a history of fractures and fracture risk. Decreased bone density and a history of fractures are risk factors for fractures [43]. Thus, we need to consider the possibility of confounding when interpreting the results of this study. None of the studies mentioned bone density of the study population, although six studies described the number of people with osteoporosis and the number of people taking osteoporosis drugs [19, 20,33,36-38]. The proportion of these patients varied from 1.7 to $34.3 \%$ in the six studies, although four of the six studies adjusted for a history of osteoporosis as a confounder in their analyses $[19,33,36,37]$. Additionally, three cohort studies clearly stated that people with a history of bone fractures were excluded from the study [19, 36, 40]. Third, in the lists of ARS and ACB, 28 drugs are not approved in Japan because both scales were developed in the USA. On the other hand, drugs that are approved in Japan but not in the USA, such as eperisone, were not evaluated in the development of these scales. Forth, we were unable to retrieve the information about the anticholinergic doses and concomitant drugs from the included studies. Not only anticholinergic drugs, but also sedatives such as benzodiazepines have been reported to be risk factors for inducing fractures [44]. Finally, the number of studies included in the meta-analysis was small, thus limiting the validity of the result.

\section{Conclusions}

Anticholinergic drug use increases fracture risk overall. However, the relationship between the anticholinergic burden and fracture risk may differ depending on the anticholinergic burden scale used. We propose that healthcare professionals should comprehensively assess the prescribed anticholinergic drugs with physicians to prevent the risk of fractures.

\section{Abbreviations}

ACB: anticholinergic cognitive burden; ADS: anticholinergic drug scale; ARS: anticholinergic risk scale; Cl: confidence interval; DBI-Ach: drug burden index-anticholinergic component; HR: hazard ratio; OR: odds ratio; RoBANS: risk bias assessment tool for non-randomized studies; RR: risk ratio

\section{Supplementary Information}

The online version contains supplementary material available at https://doi. org/10.1186/s40780-021-00213-y

Additional file 1. Forest plot of meta-analysis of fracture risk associated with anticholinergic burden using ADS.

Additional file 2. Summary of results for patients aged 65 years and above.

Additional file 3. Funnel plots of the meta-analyses of fracture risk associated with anticholinergic burden: a) ARS, b) ACB, c) ADS, d) DBI-Ach.

Additional file 4. Thirty-five drugs included in both ARS and ACB.

\section{Acknowledgements}

We would like to thank Teresa Nakatani for English language editing.

\section{Authors' contributions}

All authors conceived and designed the study. $\mathrm{YO}$ and $\mathrm{TH}$ conducted the literature search and were responsible for statistical analysis of the data. All authors involved in the interpretation of data. All authors read and approved the final manuscript. 


\section{Funding}

There are no funding sources for this study.

\section{Availability of data and materials}

The datasets used and/or analyzed during the current study are available from the corresponding author on reasonable request.

\section{Declarations}

\section{Ethics approval and consent to participate}

Not applicable.

\section{Consent for publication}

Not applicable.

\section{Competing interests}

The authors declare that they have no competing interests.

\section{Author details}

'Department of Pharmacy, Faculty of Pharmacy, Musashino University, 1-1-20 Shin-machi, Nishitokyo-shi, Tokyo 202-8585, Japan. ${ }^{2}$ Department of Pharmacy, Faculty of Medicine, Mie University Hospital, Mie University, 2-174 Edobashi, Tsu, Mie 514-8507, Japan.

Received: 20 April 2021 Accepted: 10 June 2021

Published online: 01 September 2021

\section{References}

1. Sumukadas D, McMurdo ME, Mangoni AA, Guthrie B. Temporal trends in anticholinergic medication prescription in older people: repeated crosssectional analysis of population prescribing data. Age Ageing. 2014;43(4): 515-21. https://doi.org/10.1093/ageing/aft199.

2. By the 2019 American Geriatrics Society Beers Criteria ${ }^{\oplus}$ Update Expert Panel. American Geriatrics Society 2019 Updated AGS Beers Criteria ${ }^{\circledR}$ for Potentially Inappropriate Medication Use in Older Adults. J Am Geriatr Soc. 2019; 67: 674-94

3. O'Mahony D, O'Sullivan D, Byrne S, O'Connor MN, Ryan C, Gallagher P. STOPP/START criteria for potentially inappropriate prescribing in older people: version 2. Age Ageing. 2015;44(2):213-8. https://doi.org/10.1093/a geing/afu145

4. The Japan Geriatric Society. Guidelines for medical treatment and its safety in the elderly 2015. Tokyo: Medical View; 2015

5. Lee SH, Hsu WT, Lai CC, Esmaily-Fard A, Tsai YW, Chiu CC, et al. Use of antipsychotics increases the risk of fracture: a systematic review and metaanalysis. Osteoporos Int. 2017;28(4):1167-78. https://doi.org/10.1007/s00198016-3881-3

6. Vestergaard P, Rejnmark L, Mosekilde L. Selective serotonin reuptake inhibitors and other antidepressants and risk of fracture. Calcif Tissue Int 2008:82(2):92-101. https://doi.org/10.1007/s00223-007-9099-9.

7. Yehoshua A, Chancellor M, Vasavada S, Malone DC, Armstrong EP, Joshi M, et al. Health resource utilization and cost for patients with incontinent overactive bladder treated with anticholinergics. J Manag Care Spec Pharm. 2016;22(4):406-13. https://doi.org/10.18553/jmcp.2016.22.4.406.

8. Nurminen J, Puustinen J, Piirtola M, Vahlberg T, Lyles A, Kivelä SL. Opioids, antiepileptic and anticholinergic drugs and the risk of fractures in patients 65 years of age and older: a prospective population-based study. Age Ageing. 2013;42(3):318-24. https://doi.org/10.1093/ageing/afs178.

9. Vestergaard P, Rejnmark L, Mosekilde L. Fracture risk associated with parkinsonism and anti-Parkinson drugs. Calcif Tissue Int. 2007;81(3):153-61. https://doi.org/10.1007/s00223-007-9065-6.

10. Hagino H, Endo N, Harada A, Iwamoto J, Mashiba T, Mori S, et al. Survey of hip fractures in Japan: recent trends in prevalence and treatment. J Orthop Sci. 2017;22(5):909-14. https://doi.org/10.1016/j.jos.2017.06.003.

11. Ministry of Health, Labour and Welfare. In: Comprehensive Survey of Living Conditions. https://www.mhlw.go.jp/toukei/saikin/hw/k-tyosa/k-tyosa19/dl/ 05.pdf. Accessed 10 Nov 2020.

12. Kannus $\mathrm{P}$, Sievänen $\mathrm{H}$, Palvanen $\mathrm{M}$, Järvinen $\mathrm{T}$, Parkkari J. Prevention of falls and consequent injuries in elderly people. Lancet. 2005;26:1885-93.

13. The Statistics Bureau of Japan. In: Results of the Population Estimates. https://www.stat.go.jp/data/jinsui/pdf/202009.pdf. Accessed 6 Oct 2020.
14. Rudolph JL, Salow MJ, Angelini MC, McGlinchey RE. The anticholinergic risk scale and anticholinergic adverse effects in older persons. Arch Intern Med. 2008;10:508-13

15. Boustani M, Campbell N, Munger S, Maidment I, Fox C. Impact of anticholinergics on the aging brain: a review and practical applicaiton. Aging Health. 2008;4(3):311-20. https://doi.org/10.2217/1745509X.4.3.311.

16. Campbell N, Maidment I, Fox C, Khan B, Boustani M. The 2012 update to the anticholinergic cognitive burden scale. J Am Geriatr Soc. 2013;61:S142-

17. Carnahan RM, Lund BC, Perry PJ, Pollock BG, Culp KR. The anticholinergic drug scale as a measure of drug-related anticholinergic burden: associations with serum anticholinergic activity. J Clin Pharmacol. 2006;46(12):1481-6. https://doi.org/10.1177/0091270006292126.

18. Hilmer SN, Mager DE, Simonsick EM, Cao Y, Ling SM, Windham BG, et al. A drug burden index to define the functional burden of medications in older people. Arch Intern Med. 2007;23:781-7

19. Chatterjee S, Bali V, Carnahan RM, Chen H, Johnson ML, Aparasu RR. Anticholinergic medication use and risk of fracture in elderly adults with depression. J Am Geriatr Soc. 2016;64(7):1492-7. https://doi.org/10.1111/ jgs.14182.

20. Hsu WH, Wen YW, Chen LK, Hsiao FY. Comparative associations between measures of anti-cholinergic burden and adverse clinical outcomes. Ann Fam Med. 2017;15(6):561-9. https://doi.org/10.1370/afm.2131.

21. Reinold J, Schäfer W, Christianson L, Barone-Adesi F, Riedel O, Pisa FE. Anticholinergic burden and fractures: a systematic review with methodological appraisal. Drugs Aging. 2020;37(12):885-97. https://doi.org/1 0.1007/s40266-020-00806-6.

22. Lertxundi U, Domingo-Echaburu S, Hernandez R, Peral J, Medrano J. Expertbased drug lists to measure anticholinergic burden: similar names, different results. Psychogeriatrics. 2013;13(1):17-24. https://doi.org/10.1111/j.1479-83 01.2012.00418.x

23. Naples JG, Marcum ZA, Perera S, Gray SL, Newman AB, Simonsick EM, et al. Concordance between anticholinergic burden scales. J Am Geriatr Soc. 2015;63(10):2120-4. https://doi.org/10.1111/jgs.13647.

24. Pont LG, Nielen JT, McLachlan AJ, Gnjidic D, Chan L, Cumming RG, et al. Measuring anticholinergic drug exposure in older community-dwelling Australian men: a comparison of four different measures. Br J Clin Pharmacol. 2015:80(5):1169-75. https://doi.org/10.1111/bcp.12670.

25. Moher D, Liberati A, Tetzlaff J, Altman DG, PRISMA group. Preferred reporting items for systematic reviews and meta-analyses: the PRISMA statement. Ann Intern Med. 2009;151:264-9.

26. Kim SY, Park JE, Lee YJ, Seo HJ, Sheen SS, Hahn S, et al. Testing a tool for assessing the risk of bias for nonrandomized studies showed moderate reliability and promising validity. J Clin Epidemiol. 2013;66(4):408-14. https:// doi.org/10.1016/j.jclinepi.2012.09.016.

27. Pedersen JE, Ängquist LH, Jensen CB, Kjærgaard JS, Jess T, Allin KH. Risk of pancreatitis in patients with inflammatory bowel disease - a meta-analysis. Dan Med J. 2020;67:A08190427.

28. Xing D, Ma XL, Ma JX, Wang J, Yang Y, Chen Y. Association between use of benzodiazepines and risk of fracutures: a meta-analysis. Osteopros Int. 2014; 25(1):105-20. https://doi.org/10.1007/s00198-013-2446-y.

29. Donnelly K BR, Hewitt J, Routledge PA, Carter B. Benzodiazepines, Z-drugs and the risk of hip fracture: A systematic review and meta-analysis. PLoS One. 2017; doi: https://doi.org/10.1371/journal.pone.0174730.

30. Higgins JPT, Thomas J, Chandler J, Cumpston M, Li T, Page MJ, Welch VA (editors). Cochrane Handbook for Systematic Reviews of Interventions, Version 6.2 [updated February 2021]: Cochrane, 2021. www.training.cochra ne.org/handbook. Accessed 26 May 2021.

31. Higgins JPTS, Deeks JJ, Altman DG. Measuring inconsistency in metaanalyses. BMJ. 2003;327(7414):557-60. https://doi.org/10.1136/bmj.327.7414. 557.

32. Begg CB, Mazumdar M. Operating characteristics of a rank correlation test for publication bias. Biometrics. 1994;50(4):1088-101. https://doi.org/10.23 07/2533446

33. Bali V, Chatterjee S, Johnson ML, Chen H, Carnahan RM, Aparasu RR. Comparative risk of hip fractures in elderly nursing home patients with depression using paroxetine and other selective serotonin reuptake inhibitors. J Comp Eff Res. 2016:5(5):461-73. https://doi.org/10.2217/cer-201 6-0009.

34. Crispo JA, Willis AW, Thibault DP, Fortin Y, Hays HD, McNair DS, et al. Associations between anticholinergic burden and adverse health outcomes 
in Parkinson disease. PLoS One. 2016;11(3):e0150621. https://doi.org/10.13 71/journal.pone.0150621.

35. Ishida JH, McCulloch CE, Steinman MA, Grimes BA, Johansen KL. Psychoactive medications and adverse outcomes among older adults receiving hemodialysis. J Am Geriatr Soc. 2019;67(3):449-54. https://doi. org/10.1111/jgs.15740

36. Kao LT, Huang CY, Lin HC, Chu CM. No increased risk of fracture in patients receiving antimuscarinics for overactive bladder syndrome: a retrospective cohort study. J Clin Pharmacol. 2018;58(6):727-32. https://doi.org/10.1002/ jcph.1067.

37. Lu WH, Wen YW, Chen LK, Hsiao FY. Effect of polypharmacy, potentially inappropriate medications and anticholinergic burden on clinical outcomes: a retrospective cohort study. CMAJ. 2015;3:E130-7.

38. Machado-Duque ME, Castaño-Montoya JP, Medina-Morales DA, CastroRodríguez A, González-Montoya A, Machado-Alba JE. Drugs with anticholinergic potential and risk of falls with hip fracture in the elderly patients: a case-control study. J Geriatr Psychiatry Neurol. 2018;31(2):63-9. https://doi.org/10.1177/0891988718757370.

39. Moga DC, Carnahan RM, Lund BC, Pendergast JF, Wallace RB, Torner JC, et al. Risks and benefits of bladder antimuscarinics among elderly residents of veterans affairs community living centers. J Am Med Dir Assoc. 2013; 14(10):749-60. https://doi.org/10.1016/j.jamda.2013.03.008.

40. Sørensen HJ, Jensen SO, Nielsen J. Schizophrenia, antipsychotics and risk of hip fracture: a population-based analysis. Eur Neuropsychopharmacol. 2013; 23(8):872-8. https://doi.org/10.1016/j.euroneuro.2013.04.002.

41. Woolcott JC, Richardson KJ, Wiens MO, Patel B, Marin J, Khan KM, et al. Meta-analysis of the impact of 9 medication classes on falls in elderly persons. Arch Intern Med. 2009;23:1952-60.

42. Kose E, Hirai T, Seki T. Anticholinergic drugs use and risk of hip fracture in geriatric patients. Geriatr Gerontol Int. 2018;18(9):1340-4. https://doi.org/1 $0.1111 /$ ggi.13486.

43. Marshall D, Johnell O, Wedel H. Meta-analysis of how well measures of bone mineral density predict occurrence of osteoporotic fractures. BMJ. 1996;18:1254-9.

44. Xing D, Ma XL, Ma JX, Wang J, Yang Y, Chen Y. Association between use of benzodiazepines and risk of fractures: a meta-analysis. Osteoporos Int. 2014; 25(1):105-20. https://doi.org/10.1007/s00198-013-2446-y.

\section{Publisher's Note}

Springer Nature remains neutral with regard to jurisdictional claims in published maps and institutional affiliations.

Ready to submit your research? Choose BMC and benefit from:

- fast, convenient online submission

- thorough peer review by experienced researchers in your field

- rapid publication on acceptance

- support for research data, including large and complex data types

- gold Open Access which fosters wider collaboration and increased citations

- maximum visibility for your research: over $100 \mathrm{M}$ website views per year

At $\mathrm{BMC}$, research is always in progress.

Learn more biomedcentral.com/submissions 